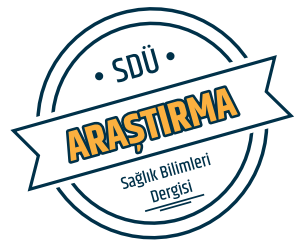

\title{
İdrar Örneklerinde Saptanan Escherichia Coli Suşlarının Antibiyotik Duyarlılığı
} Antibiotic Sensitivity of the Escherichia Coli Strains Identified from Urine Samples

\author{
Mustafa Güzel' ${ }^{1}$, Doğan Akdoğan² \\ ${ }^{1}$ Özel Maltepe Tıp Merkezi Mikrobiyoloji Laboratuvarı, İstanbul, Türkiye. \\ 229 Mayıs Devlet Hastanesi Mikrobiyoloji Laboratuvarı, Ankara, Türkiye.
}

\section{Özet}

Amaç: Bu çalışmada, Fosfomisin ve diğer antibiyotiklerin genişlemiş spektrumlu beta-laktamaz (GSBL) negatif ve pozitif Escherichia Coli (E. Coli) suşlarına karşı duyarlılık oranları incelenmesi amaçlanmıştır.

Materyal-Method: İdrar kültürlerinden izole edilen 100 GSBL pozitif ve $100 \mathrm{GSBL}$ negatif E. Coli suşu çalışmaya dâhil edilmiştir. Antibiyotik duyarlılıkları Kirby-Bauer disk difüzyon yöntemi ve/veya Phoenix 100 otomatize sistemi kullanılarak, GSBL varlığı ise kombine disk difüzyon yöntemi ile araştırılmıştır.

Bulgular: E.coli suşlarının Fosfomisin'e karşı duyarlılık oranları GSBL pozitiflerde $\% 96$, GSBL negatiflerde ise \%98 olarak saptanmış olup, benzer olduğu görülmüştür. İmipenem'e dirençli suş bulunmamış olup, GSBL negatif suşların tedavide kullanılan diğer antibiyotiklere karşı GSBL pozitif suşlardan daha yüksek oranda duyarlıllk gösterdiği tespit edilmiş̧ir.

Sonuç: Sonuç olarak tek doz kullanım kolaylığı da olan Fosfomisin'in hem GSBL pozitif hem de GSBL negatif E. Coli suşlarının etkeni olduğu komplike olmayan üriner sistem infeksiyonlarının tedavisinde kullanılabileceği düşünülmüştür.

Anahtar kelimeler: İdrar, Escherichia Coli, BetaLaktamaz, Bakteri Duyarlılık Testleri

\begin{abstract}
Objective: In this study, we aimed to evaluate the sensitivity of Fosfomycin and the other antibiotics against extended spectrum beta-lactamase (ESBL) negative and positive Escherichia Coli (E. Coli) strains.
\end{abstract}

Material-Method: 100 ESBL positive and 100 ESBL negative E. Coli strains isolated from urine cultures were included to the study. Antibiotic sensitivity was determined by Kirby-Bauer disk diffusion method and /or automated Phoenix with 100 systems. ESBL was investigated with combined disk diffusion method.

Results: Fosfomycin sensitivity was found as $96 \%$ and $98 \%$ in ESBL positive and negative E. Coli strains, respectively. It was found that, there was no İmipenem resistant strain, and the ESBL negative strains shown higher sensitivity rate than ESBL positive strains against the other antibiotics used in treatment.

Conclusions: As a result, it was thought that, the Fosfomycin, which is also easy to use in a single dose, can be used in the treatment of uncomplicated urinary system infections caused by both ESBL positive and ESBL negative E. coli strains.

We consider that the reasons why no early complication are the patient selection, careful follow-up, and treatment of the patients in a newly established transplantation center.

Keywords: Urine, Escherichia Coli, Beta-Lactamase, Bacterial Sensitivity Tests

\section{Giriş}

Üriner sistem infeksiyonlarının (ÜSì), sık karşılaşılan infeksiyon türlerinden birisi olduğu bilinmektedir (1). Yenidoğan'dan yaşlılığa kadar her yaş grubunda görülen ÜSI'nin sıklığı yaş arttıkça artarak, 80 yaş ve üzerinde $\% 30$ 'a çıkmakta, ayrıca anatomik özellikleri nedeniyle kadınlarda daha fazla görülebilmektedir (2). Gebe olmayan ve üriner sisteminde yapısal ya da anatomik sorunu olmayan kadınlarda görülen akut sistit, komplike olmayan ÜSİ olarak tanımlanmakta, bunun dışında kalanlar ise komplike ÜSİ olarak sinıflandırılmaktadır (3). Komplike olmayan ÜSI'nun tanısında bulgu ve belirtilerin yanı sira, kullanılan laboratuvar testleri arasında idrarda lökosit esteraz ve nitrit düzeyi ve idrar kültürü yer almaktadır. İdrar kültürü özellikle

komplike ÜSİ'de etkenin ve antibiyotik duyarlılığının tespitinde kullanılabilmektedir. Mesaneden doğrudan kateter veya suprapubik aspirasyon ile alınan idrar kültürü altın standart olmakla birlikte, girişim zorluğu ve hasta toleransı nedeniyle, bu yöntemlerin yerine orta akım idrar örneği tercih edilmektedir (4). Virülans faktörleri ve fenotipik özellikleri ile kommensal Escherichia Coli (E. Coli) türlerinden farkl1lık gösteren üropatojen E. Coli türleri, ÜSİ'de en sik saptanan mikroorganizmalardır (5). E. Coli'nin etkeni olduğu toplum kökenli ÜSI'nin ampirik tedavisinde beta-laktam grubu antibiyotikler, beta-laktam ve beta-laktamaz inhibitörü kombinasyonları, kinolonlar ve trimetoprim-sulfametoksazol sık kullanılan antibiyotikler olup, direnç oranının artması ve uzun süreli tedavilerde oluşabilecek komplikasyonlar

DOI: $10.22312 /$ sdusbed.283279

Müracaat tarihi: 21.10 .2016

Kabul tarihi: 08.03.2017

Yazışma Adresi / Corresponding: Mustafa Güzel,

Güzeltepe Mah. Çağdaş Sok. No:7 Üsküdar, İstanbul, Türkiye.

Tel: 05324843250
Fax: 02164594779

E-mail: dr.mustafaguzel@hotmail.com 
nedeniyle, günümüzde farklı tedavi seçenekleri gündeme gelmektedir (6). En sık saptanan direnç mekanizmalarından birisi olan genişlemiş spektrumlu beta-laktamaz (GSBL) varlığı ise yalnızca hastane kökenli infeksiyonlarda değil, toplum kökenli infeksiyonlarda da gittikçe artan oranlarda saptanmaktadır (7). Tek doz kullanım kolaylığı, yan etkilerinin az olması ve düşük direnç oranı nedeniyle fosfomisin tedavide alternatif olabilecek antibiyotiklerdendir. Ayrica, sistit ve gebelikteki asemptomatik ÜSİ'nin tedavisinde güvenli ve etkili bir seçenek ve birçok ülkede sistitin tedavisinde ilk sirada tercih edilmektedir (8).

Streptomyces viridochromogenes, Streptomyces wedmorensis ve Streptomyces fradiae türlerinin bir fermentasyon ürünü olan fosfomisin, bakterinin MurA enzimini inhibe ederek peptidoglikan tabakasının sentezini engellemektedir. Ayrıca bakteri fimbrialarının hareket yeteneklerini ve sentezini azaltan Fosfomisin, hem Gram negatif hem de Gram pozitif üriner sistem patojenlerinin, üriner sistemin epiteline ve idrar yollarında kullanılan kateterlerin iç yüzeyine yapışması ve kolonizasyonunu engellemektedir (9). Fosfomisin çoklu ilaç direncine sahip türleri dahil birçok Gram pozitif ve Gram negatif etkene karşı invitro yüksek etkinliğe sahiptir ve klinikte ÜSİ'nda alternatif bir tedavi seçeneğidir (10).

Bu çalışmada, Fosfomisinin GSBL negatif ve GSBL pozitif E. coli suşlarındaki duyarlılık oranları incelenmesi ve GSBL varlığının Fosfomisin ve diğer antibiyotiklere karşı duyarlılığı üzerine olan etkisinin araştırılması amaçlanmıştır.

\section{Materyal-Method}

Bir üniversite hastanesinin Tıbbi Mikrobiyoloji Laboratuarı'na Temmuz 2013-Ağustos 2015 tarihleri arasında çeşitli polikliniklere başvuran hastalardan gönderilen ve anlamlı $\mathrm{E}$. Coli üremesi tespit edilen 200 idrar örneği çalışmaya dâhil edilmiştir. 100 örnek GSBL pozitif, 100 örnek ise GSBL negatif olarak belirlenmiştir. Çalışmanın tüm aşamalarında Helsinki Deklarasyonu Prensiplerine uygunluk esas alınmıştır.
İdrar örnekleri \%5 koyun kanlı agar ve Eozin Metilen Mavisi (EMB) agara (Oxoid, İngiltere) ekim yap 1 larak, 24 saat $37^{\circ} \mathrm{C}$ ' de inkübe edilmiştir. Üreyen bakterilerin tanımlanmasında, Gram boya ile boyanma özelliği, besiyerindeki koloni morfolojisi, üreaz varlığı, indol oluşumu, glukoz fermentasyonu, laktoz fermentasyonu, sitrat kullanımı gibi konvansiyonel yöntemler ve Phoenix 100 ID / AST (Becton Dickinson Co., Sparks, MD., ABD) otomatik tanılama sistemi kullanılmıştır. Antibiyotik duyarlılıkları, Klinik ve Laboratuvar Standartları Enstitüsü (Clinical and Laboratory Standards Institute) standartlarına göre, Kirby-Bauer disk difüzyon yöntemi ve / veya Phoenix 100 ID / AST otomatik sistemi, GSBL pozitif ve negatifliği ise kombine disk difüzyon yöntemi kullanılarak saptanmıștır (7). Fosfomisin, Ampisilin, Amoksisilin / Klavulanik asit, Sefazolin, Piperasilin, Piperasilin / Tazobaktam, Seftriakson, Sefepim, İmipenem, Gentamisin, Siprofloksasin, Trimetoprim/Sülfametoksazol için antibiyotik duyarlılığı bakılmıştır. Dirençli ve orta duyarlı bulunan suşlar dirençli olarak kabul edilmiştir.

Verilerin analizinde SPSS versiyon 15.0 istatistiksel paket programı (SPSS Inc., Chicago, IL) kullanılmıştır. Antibiyotik duyarlılığının dağılımını göstermede tanımlayıcı istatistiklerden yüzde (\%) kullanılmış, GSBL negatif ve pozitif gruplar arasında antibiyotik duyarlılığının karşılaştırmada Fisher'in Kesin Testi ve Pearson Ki-kare Testi kullanılmıştır. $\mathrm{p}<0,01$ değeri istatistiksel olarak anlamlı kabul edilmiştir.

\section{Bulgular}

Çalışmaya dâhil edilen 200 suşun, 100’ü (\%50) GSBL pozitif, 100 'ü (\% 50) ise GSBL negatif örneklerden randomize olarak belirlenmiştir. E.coli'nin Fosfomisin'e duyarlılık oranları GSBL pozitif ve GSBL negatif suşlarda sırasıyla $\% 96$ ve $\% 98$ olarak bulunmuş, aradaki bu farkın istatistiksel olarak anlamlı olmadığı saptanmıştır. Ayrıca her iki suşta da örneklerin tamamında İmipenem'e duyarlılık saptanmıştır (Tablo 1).

Bununla birlikte, diğer antibiyotiklere karşı duyarlılık açısından suşlar arasında istatistiksel olarak anlamlı farklar

Tablo 1. E. Coli suşlarının tedavide kullanılabilecek antibiyotiklere olan duyarlılık yüzdeleri*

\begin{tabular}{|c|c|c|c|c|}
\hline Antibiyotik & GSBL negatif (\%) & GSBL pozitif (\%) & $\mathbf{X}^{2}$ & $\mathbf{p}$ \\
\hline Fosfomisin & 98 & 96 & $* *$ & 0,683 \\
\hline Ampisilin & 51 & - & $68,456 * * *$ & $<0,001$ \\
\hline Amoksisilin/Klavulanik asit & 87 & 49 & $33,180 * * *$ & $<0,001$ \\
\hline Sefazolin & 65 & - & $96,296 * * *$ & $<0,001$ \\
\hline Piperasilin & 60 & - & $85,714 * * *$ & $<0,001$ \\
\hline Piperasilin/Tazobaktam & 100 & 76 & $27,273 * * *$ & $<0,001$ \\
\hline Seftriakson & 96 & - & $184,615 * * *$ & $<0,001$ \\
\hline Sefepim & 100 & - & $200,000 * * *$ & $<0,001$ \\
\hline İmipenem & 100 & 100 & - & - \\
\hline Gentamisin & 92 & 55 & $35,143 * * *$ & $<0,001$ \\
\hline Siprofloksasin & 82 & 30 & $54,870 * * *$ & $<0,001$ \\
\hline Trimetoprim/sülfametoksazol & 74 & 31 & $37,073 * * *$ & $<0,001$ \\
\hline
\end{tabular}

*Yüzdeler sütun yüzdesidir. ** Fisher’in Kesin Testi kullanılmıștır. *** Pearson Ki-kare Testi kullanılmıștır 
bulunmuştur. GSBL negatif suşta \%51 Ampisilin duyarlılı̆̆1, $\% 65$ Sefazolin duyarlılığ $1, \% 60$ Piperasilin duyarlılı̆̆ 1 , \%96 Seftriakson duyarlılığ ve \%100 Sefepim duyarlılığı varken, GSBL pozitif suşta bu antibitoriklerin hiçbirine karşı duyarlılık olmadığ saptanmıştır. Amoksisilin/klavulanik asit duyarlılığı GSBL negatif suşta \%87 iken, GSBL pozitif suşta \%49'dur. GSBL negatif suşta \%100 Piperasilin/Tazobaktom duyarlılığ varken, GSBL pozitif sușta $\% 76$ duyarlılık vardır. Gentamisin duyarlılığı GSBL negatif suşta \%92 iken, GSBL pozitif suşta \%55 olarak bulunmuştur. GSBL negatif suşta \%82 Siprofloksasin duyarlılığı varken, GSBL pozitif suşta Siprofloksasin duyarlılığ $1 \% 30$ 'dur. Saptanan bu farklılıklar istatistiksel olarak anlamlı bulunmuştur (tamamı için $p<0,001)$ (Tablo 1).

\section{Tartışma}

Üriner sistem infeksiyonlarında E. Coli'nin en sik etken olduğu bilinmektedir (1). Avrupa'da Ekim 2003 ve 2006 tarihleri arasında dokuz ülkede yapılan, komplike olmayan ÜSİ etkenlerinin antibiyotik duyarlılıklarının araştırıldığ 1 çok uluslu bir çalışmada E. Coli \% 76,7 sıklıkla etken olarak bulunmuştur (12). Ülkemizde yapılan çeşitli çalışmalara bakıldığında da ÜSİye E coli'nin \%62,5 ile \%80 arasında değişen oranlarda sebep olduğu görülmektedir (13-15). Genişlemiş spektrumlu beta-laktamaz varlığı ise ÜSI etkenlerinde sıklıkla karşımıza çıkmaktadır. Toplum kaynaklı GSBL pozitif E. Coli ile üriner sistem infeksiyonu gelişmesi için risk faktörleri, 60 yaş üzeri olmak, son 3 ayda hastaneye yatmış olmak, son üç ayda antibiyotik kullanımı, erkek cinsiyet, DM, tekrar eden idrar yolu infeksiyonu, yakın zamanda üriner kateterizasyon, ayaktan tedavi merkezlerinde takip olarak tanımlanmaktadır (16). Ülkemizde yapılan bir çalışmada Doğru ve ark. E. Coli suşlarındaki GSBL oranını $\% 14$, Çalışkan ve ark. ayaktan başvuran hastalardaki üriner sistem infeksiyonu etkeni E. Coli suşlarında bu oranı \%20, Uğur ve ark. poliklinik hastalarının idrar kültürlerinde bu oranı \%27 olarak bulmuşlardır $(7,15,17)$. GSBL pozitif suşların beta-laktamazlar dışında diğer birçok antibiyotiğe karşı da direnç gösterdiği bilinmektedir. Ayrıca kinolonlar, Trimetoprim/sülfametoksazol, metronidazol ve aminoglikozit kullanımının, ilerleyen dönemlerde GSBL pozitif etkenler ile infeksiyon oluşmasına neden olabileceği bildirilmektedir (18).

Türkiye'de yapılan çalışmalarda GSBL negatif E. Coli suşlarında Fosfomisin duyarlılı̆̆ $\% 90$ ile \%100 arasında, GSBL pozitif suşlarında ise $\% 85$ ile $\% 100$ arasında değişmekle beraber, GSBL negatif grupta Fosfomisin duyarlılığ 1 GSBL pozitif gruba göre yüksek saptanmıştır (14, 19-22). Benzer olarak yapılan bir çalışmada Hirsch ve ark. üriner sistem örneklerinden izole ettikleri E. Coli suşlarının tamamının Fosfomisine duyarlı olduğunu bildirmişlerdir (23). Zykov ve ark. GSBL pozitif E. Coli suşlarında Fosfomisin direnci saptamamışlardır (24). Yine Mittal ve ark. çoklu ilaç direnci olan üropatojen E. Coli suşlarının tamamını fosfomisine duyarlı olarak tespit etmişlerdir (25). Li ve ark. çalışmasında ise çeşitli klinik örneklerden izole edilen 1109 E. Coli suşunda Fosfomisin direnç oranını \% 7,8 olarak bildirmişler, GSBL sıklığını \%65,9 olarak saptadıkları idrar örneklerinde ise Fosfomisine \%95 oranında duyarlılık olduğunu tespit etmişlerdir (26). Bizim çalışmamızda ise GSBL negatif ve pozitif gruplarda benzer olarak yüksek duyarlılık oranları bulunmuştur.

Amerika Enfeksiyon Hastalıkları Derneği (Infectious Diseases Society of America) ve Avrupa Klinik Mikrobiyoloji ve Enfeksiyon Hastalıkları Derneği (European Society for Clinical Microbiology and Infectious Diseases) güncel kılavuzlarına göre, yetişkin kadınlarda akut komplike olmayan ÜSİ tedavisinde, fosfomisin, nitrofurantoin ve Trimetoprim/ Sülfametoksazol birinci basamak tedavi seçeneği olarak önerilmektedir (27). Ceran ve ark.'ları komplike olmayan alt ÜSI'u olan erişkin hastalarda, tek doz 3 gr fosfomisin, günde iki kez 500 mg siprofloksasine göre, hem klinik hem de mikrobiyolojik kür başarısı açısından üstün bulmuştur (28). Fosfomisin'in yan etkileri genellikle hafif ve geçicidir. S1klıkla görülen yan etkileri arasında; ishal (\%4-10), vajinit (\%5), baş ağrısı (\%2), epigastrik ağrı (\%1-2), dispepsi (\%1-2) ve halsizlik $(<\% 1)$ yer almaktadır (29).

Uğur ve ark. ayaktan hastaların idrar örneklerinden üretilen kültürlerde üreyen GSBL negatif E. Coli suşlarında Ampisilin duyarlılığını \%40, GSBL pozitif suşlarda ise $\% 0$ olarak raporlarken, Bayram ve ark. servis ve polikliniklerden gönderilen erişkin hastaların idrar örneklerinden izole ettikleri GSBL negatif E. Coli suşlarında Ampisilin duyarlılığını \%56, GSBL pozitif suşlarda ise \%11 olduğunu bildirmiştir (13, 14). Bu sonuçlar bizim çalışmamızla benzerlik göstermektedir. Amoksisilin / Klavulonik asit duyarlılığı sonuçları ise Türkiye'den yapılan çalışmalarda GSBL negatif E. Coli suşlarında \%60-\%74 arasında, GSBL pozitif suşlarda ise $\% 10-\% 38$ arasında değişirken $(14,17$, 21), bizim çalışmamızda nispeten daha yüksek bulunmuştur. Bayram ve ark. GSBL negatif E. Coli suşlarında Sefazolin duyarlılığını \%87, GSBL pozitif suşlarda ise \%11 olarak bulmuşken, bizim çalışmamızda hem GSBL negatif hem de pozitif suşlarda duyarlılık yüzdeleri daha düşüktür (14).

Tayvan'da bir hastanede 2 yıllık verilerle yapılan çalışmada, acil servise ayaktan başvuran hastaların idrarlarından elde edilen GSBL negatif E. Coli suşlarında Piperasilin duyarlılı̆̆1 \%30 olarak bulunurken, GSBL pozitif suşların tamamında Piperasiline karşı direnç saptanmıştır (30). Bizim çalışmamızda da benzer şekilde, GSBL pozitif suşların tamamında direnç varken, GSBL negatif suşlarda nispeten duyarlılık daha yüksek olarak bulunmuştur. Piperasilin / Tazobaktam kombinasyonu duyarlılığını ise, Bayram ve ark. GSBL negatif E. Coli suşlarında \%86, GSBL pozitif suşlarda ise $\% 59$ olarak bildirirken, Uğur ve ark., bizim çalışmamızla da benzer olacak şekilde, GSBL negatif E. Coli suşlarında $\% 97$, GSBL pozitif suşlarda \%79 olarak bulmuştur $(14,17)$.

Uğur ve ark. GSBL negatif E. Coli suşlarında hem Seftriakson hem de Sefepim duyarlılıklarını \%100 bulurken, GSBL pozitif suşlarda Seftriakson ve Sefepim duyarlılıklarını sırasıyla \%4 ve \%17 olarak saptamışlardır (17). Bizim çalışmamızda ise GSBL negatif suşlarda Seftriakson duyarlılığ $\% 100$, Sefepim 
duyarlılı̆̆ 1 ise \%96 iken, GSBL pozitif suşlarda ise her iki antibiyotik içinde \%0 olarak bulunmuştur. Yapılan birçok çalışmada hem GSBL negatif hem de GSBL pozitif E. Coli suşlarında İmipenem duyarlılığ $1 \% 100$ olarak bildirilmiştir $(14,20,22)$. Bizim çalışmamızda da her iki grupta da İmipenem duyarlılığı \%100 olarak saptanmıştır.

Çalışmamızda aminoglikozit grubunda yer alan Gentamisin duyarlılığı GSBL negatif E. Coli suşlarında \%92, GSBL pozitif suşlarda ise \%55 bulunmuştur. Ülkemizde yapılan çalışmalarda aminoglikozit grubu antibiyotik duyarlılıkları GSBL negatif E. Coli suşlarında \%65 ile \%100 arasında, GSBL pozitif suşlarda ise $\% 30$ ile $\% 100$ arasında değişmekle beraber, Pullukçu ve ark. çalışmaları hariç, diğer çalışmalarda GSBL negatif grupta aminoglikozit duyarlılığ $\mathrm{GSBL}$ pozitif gruba göre yüksek saptanmıştır (14, 19-22).

Son olarak, çalışmamızda değerlendirdiğimiz antibiyotikler olan Siprofloksasin ve Trimetoprim / Sülfometoksazol duyarlılıkları sırasıyla GSBL negatif E. Coli suşlarında \%82 ve $\% 74$, GSBL pozitif suşlarda ise $\% 30$ ve $\% 31$ bulunmuştur. Türkiye'de yapılan çalışmalarda ise benzer şekilde Siprofloksasin duyarlılıkları GSBL negatif E. Coli suşlarında $\% 65$ ile $\% 89$ arasında, GSBL pozitif suşlarında ise \%25 ile $\% 65$ arasında değişmektedir. Trimetoprim / Sülfometoksazol duyarlılıkları ise GSBL negatif E. Coli suşlarında \%50 ile $\% 66$ arasında, GSBL pozitif suşlarda $\% 20$ ile $\% 55$ arasında olduğu bildirilmiştir (14, 19-22).

\section{Çalışmanın kısıtlılıkları ve güçlü yanları}

Çalışmamız laboratuvar temelli bir çalışma olmasından dolayı, idrar örnekleri alınan hastaların demografik özellikleri, klinik özellikleri, ÜSİ'nun lokalizasyonu (alt / üst), örnek alım döneminde antibiyotik kullanımları ile ilgili özellikleri analize dâhil edilememiştir. Antibiyotik duyarlılığını doğrudan etkileyebilen bu durumlar akılda tutularak çalışmamız bulguları ihtiyatlı değerlendirilmelidir. Ayrıca çalışmamız bir hastanede belirli sayıda idrar örneği ile yapılmış olup, sonuçların tüm topluma genellenebilirliği söz konusu değildir.

Bununla birlikte çalışmanın en önemli güçlü yanı, ÜSİ'nda geçmişte sıkça kullanılan ve gelecekte alternatif seçenekler arasında yer alan çok sayıda antibiyotiğin, idrar örneklerinde tespit edilen GSBL pozitif ve negatif E. Coli suşlarında, bir arada ve karşılaştırılmalı olarak değerlendirilmesidir.

Sonuç olarak, ülkemizde yapılan çalışmalarla benzer şekilde bizim çalışmamızda da GSBL pozitif olan suşlardaki antibiyotik duyarlılıklarının genel olarak GSBL negatif suşlardan daha düşük olduğu görülmektedir. Özellikle geçmişte ÜSİ'nın ampirik tedavisinde kullanılan antibiyotiklerde yüksek direnç oranı görülmüştür. Ayrıca, literatür bilgileri ve çalışmamız sonuçlarında göre Fosfomisin'in GSBL negatif ve pozitif E. Coli suşlarına karşı etkili bir ilaç olması nedeniyle, günümüzde toplum kaynaklı ÜSİ tedavisinde etkin bir şekilde kullanılabileceği düşünülmektedir. İdrar örneklerinin alındığ hastaların demografik ve klinik özelliklerinin de analize dahil edildiği, daha farklı antibiyotikler ile daha büyük örneklemde yapılacak çalışmalar literatüre daha değerli katkılar sunabilecektir.

\section{Teşekkür}

$\mathrm{Bu}$ çalışmada incelenen Escherichia coli suşlarının temininde yardımlarını esirgemeyen Prof. Dr. İdris Şahin'e teşekkürlerimizi sunarız.

\section{Kaynaklar}

1. O'Connell SC. Management of patients with urinary disorders. In: Smeltzer SC, Bare BG, Hinkle JL, Cheever KH, editors. Brunner\&Suddarth's Textbook of Medicalsurgical Nursing. 12. ed. ABD: Lippincott Williams \& Wilkins; 2009. p. 1359.

2. Tuncer İ, Karabayraktar A, Kart H, Baysal B. Üriner Sistem İnfeksiyonlarında Etken Mikroorganizmaların Görülme Sıklığı. SDÜ Tıp Fakültesi Dergisi. 1996; 3(3): 33-5.

3. Geerlings SE. Clinical Presentations and Epidemiology of Urinary Tract Infections. Microbiology spectrum. 2016; 4(5).

4. Pietrucha-Dilanchian P, Hooton TM. Diagnosis, Treatment, and Prevention of Urinary Tract Infection. Microbiology spectrum. 2016; 4(6)

5. Allocati N, Masulli M, Alexeyev MF, Di Ilio C. Escherichia coli in Europe: an overview. International journal of environmental research and public health. 2013; 10(12): 6235-54.

6. Köken G, Aşık G, Çiftçi İH, Çetinkaya Z, Aktepe OC, Y1lmazer M. Toplum kökenli üriner sistem infeksiyonu etkeni Escherichia coli suşlarında fosfomisin trometamol etkinliği. ANKEM Dergisi. 2008; 22(1): 23-7.

7. Doğru A, Karatoka B, Ergen P, Aydın ÖŞ, Tigen ET. İdrar yolu enfeksiyonlarında direnç oranları: 2010 yılı verilerimiz. Turkish Journal of Urology. 2013; 39(4): 237-43.

8. Garau J. Other antimicrobials of interest in the era of extended-spectrum beta lactamases: fosfomycin, nitrofurantoin and tigecycline. Clin Mikrobiol Infect. 2008; 14(1): 198-202.

9. Baylan O. Fosfomisin: Dünü, bugünü ve geleceği. Mikrobiyol Bul. 2010; 44: 311-21.

10. Karadağ A, Tanrıverdi Çaycı Y, Bilgin K, Günaydın M, Eroğlu C. In vitro efcacy of fosfomycin against clinical strains. Journal of Microbiology and Infectious Diseases. 2014; 4(2): 55-8.

11. Institute CaLS. Performance Standards for Antimicrobial Susceptibility Testing; Twenty-Fifth Informational Supplement, CLSI document. Wayne, Pa, USA: Clinical and Laboratory Standards Institute; 2013.

12. Schito GC, Naber KG, Botto H, Palou J, Mazzei T, Gualco L, et al. The ARESC study: an international survey on the antimicrobial resistance of pathogens involved in uncomplicated urinary tract infections. International journal of antimicrobial agents. 2009; 34(5): 407-13.

13. Aral M, Kireçci E, Doğan SŞ. İdrar örneklerinden izole edilen gram negatif bakteriler ve antibiyotiklere direnç oranlarının retrospektif olarak değerlendirilmesi. Türk Mikrobiyol Cem Derg. 2011; 41(4): 139-42.

14. Bayram Y, Eren H, Berktaş M. İdrar örneklerinden izole 
edilen bakteriyel patojenlerin dağılımı ve GSBL pozitif ve negatif Escherichia coli suşlarının fosfomisin ve diğer antimikrobiyallere duyarlılık paterni. ANKEM Dergisi. 2011; 25(4): 232-6.

15. Çalışkan E, Dede A, Altınöz Aytar A, Biten Güven G, Kaş E. Ayaktan başvuran hastalarda üriner sistem infeksiyonuna neden olan Esherichia coli ve Klebsiella spp. suşlarının çeşitli antibiyotiklere direnç oranlarının ve Genişlemiş spektrumlu beta-laktamaz varlığının değerlendirilmesi. ANKEM Dergisi. 2015; 29(2): 47-53.

16. Tükenmez Tigen E, Mülazımoğlu L. Toplum kökenli infeksiyonlarda genişlemiş spektrumlu $\beta$-laktamazlar ve klinik önemi. Klimik Derg. 2012; 25(3): 94-8.

17. Uğur AR, Türk Dağı H, Tuncer İ, Fındık D, Arslan U. İdrar kültürlerinden izole edilen Esherichia coli suşlarının antibiyotik duyarlılığı ve Genişlemiş spektrumlu betalaktamaz oran1. ANKEM Dergisi. 2013; 27(1): 13-8.

18. Paterson DL, Bonomo RA. Extended-spectrum betalactamases: a clinical update. Clinical microbiology reviews. 2005; 18(4): 657-86.

19. Pullukçu H, Aydemir Ş, Işıkgöz Taşbakan M, Sipahi OR, Çilli Hall Jr. F, Tünger A. Is there a rise in resistance rates to fosfomycin and other commonly used antibiotics in Escherichia coli-mediated urinary tract infections? A perspective for 2004-2011. Turk J Med Sci 2013; 43: 537-41.

20. Durmaz S, Toka Özer T, Çelik H, Yula E. Toplum kökenli üriner sistem infeksiyonlardan izole edilen Escherichia coli suşlarında fosfomisin trometamol ve bazı antibiyotiklerin in-vitro etkinliğinin araştırılması. Abant Med J. 2015; 4(4): 351-4.

21. İnci M, Yula E, Köksaldı Motor V, Davarcı M, Duran N, Kilınç Ç, et al. Nitrofurantoin ve Fosfomisinin İdrar Yolu Enfeksiyonu Etkeni Olan E. coli izolatlarına invitro etkinliği. Yeni Tıp Dergisi. 2013; 30(2): 75-8.

22. Uyanık MH, Hanc1 H, Yazg1 H. Üriner sistem infeksiyonlarından soyutlanan toplum kökenli Escherichia coli suşlarına fosfomisin trometamolün ve bazı antibiyotiklerin in-vitro etkinliği. ANKEM Dergisi. 2009; 23(4): 172-6.

23. Hirsch EB, Raux BR, Zucchi PC, Kim Y, McCoy C, Kirby $\mathrm{JE}$, et al. Activity of fosfomycin and comparison of several susceptibility testing methods against contemporary urine isolates. International journal of antimicrobial agents. 2015; 46(6): 642-7.

24. Zykov IN, Sundsfjord A, Smabrekke L, Samuelsen O. The antimicrobial activity of mecillinam, nitrofurantoin, temocillin and fosfomycin and comparative analysis of resistance patterns in a nationwide collection of ESBLproducing Escherichia coli in Norway 2010-2011. Infectious diseases (London, England). 2016; 48(2): 99-107.

25. Mittal S, Sharma M, Chaudhary U. Fosfomycin use in multi drug resistant uropathogenic Escherichia coli. Infectious disorders drug targets. 2015; 15(3): 196-201.

26. Li Y, Zheng B, Li Y, Zhu S, Xue F, Liu J. Antimicrobial Susceptibility and Molecular Mechanisms of Fosfomycin Resistance in Clinical Escherichia coli Isolates in Mainland China. PloS one. 2015; 10(8): e0135269.

27. Gupta K, Hooton TM, Naber KG, Wullt B, Colgan R, Miller LG, et al. International clinical practice guidelines for the treatment of acute uncomplicated cystitis and pyelonephritis in women: A 2010 update by the Infectious Diseases Society of America and the European Society for Microbiology and Infectious Diseases. Clinical infectious diseases : an official publication of the Infectious Diseases Society of America. 2011; 52(5): e103-20.

28. Ceran N, Mert D, Kocdogan FY, Erdem I, Adalati R, Ozyurek S, et al. A randomized comparative study of singledose fosfomycin and 5-day ciprofloxacin in female patients with uncomplicated lower urinary tract infections. Journal of infection and chemotherapy : official journal of the Japan Society of Chemotherapy. 2010; 16(6): 424-30.

29. Zhanel GG, Walkty AJ, Karlowsky JA. Fosfomycin: A First-Line Oral Therapy for Acute Uncomplicated Cystitis. The Canadian Journal of Infectious Diseases \& Medical Microbiology $=$ Journal Canadien des Maladies Infectieuses et de la Microbiologie Médicale / AMMI Canada. 2016; 2016: 2082693.

30. Hsieh C-J, Shen Y-H, Hwang K-P. Clinical Implications, Risk Factors and Mortality Following Community-onset Bacteremia Caused by Extended-spectrum $\beta$-lactamase (ESBL) and non-ESBL Producing Escherichia coli. Journal of Microbiology, Immunology and Infection. 2010; 43(3): 240-8. 